\title{
Oral liquid levothyroxine treatment at breakfast: a mistake?
}

\author{
Carlo Cappelli, Ilenia Pirola, Elena Gandossi, Annamaria Formenti and \\ Maurizio Castellano
}

Endocrine and Metabolic Unit, Clinica Medica, Department of Clinical and Experimental Sciences, University of Brescia, c/o 1^ Medicina Spedali Civili di Brescia, Piazzale Spedali Civili no. 1, 25100 Brescia, Italy
Correspondence should be addressed to C Cappelli

Email cappelli@med.unibs.it

\begin{abstract}
Objective: Taking levothyroxine ( $\left(-\mathrm{T}_{4}\right)$ with coffee or with water followed by coffee intake within a few minutes results in poor TSH response in many patients. $T_{4}$ is available in tablet form worldwide, but novel formulations in soft gel capsule or liquid form are now available.

Design: We fortuitously identified a euthyroid patient who wrongly consumed liquid L-T 4 with coffee at breakfast; after changing the time of consumption to 30 min before breakfast, no change in $\mathrm{TSH}_{1}$ free $_{4}\left(\mathrm{fT}_{4}\right.$ ), and free tri-iodothyronine ( $\mathrm{fT}_{3}$ ) concentrations was observed. Once the first patient was identified, additional stable euthyroid patients who consumed liquid $\mathrm{L}-\mathrm{T}_{4}$ with coffee were identified.

Methods: Patients were recruited by searching our 'thyroid patients' database. All the patients on liquid L- $\mathrm{T}_{4}$ treatment were contacted by phone to ask them whether they took L-T $\mathrm{T}_{4}$ at breakfast. We identified 54 patients who were submitted to $\mathrm{TSH}_{1} \mathrm{fT}_{4}$, and $\mathrm{fT}_{3}$ evaluation, with the indication that the same dosage of $\mathrm{L}-\mathrm{T}_{4}$ be consumed 30 min before breakfast. We determined their $\mathrm{TSH}_{1} \mathrm{fT}_{4}$, and $\mathrm{fT}_{3}$ concentrations after 3 and 6 months again.

Results: No significant difference in thyroid hormone concentrations was observed in patients when they consumed $\mathrm{L}_{4}$ at breakfast or when they consumed it $30 \mathrm{~min}$ before breakfast for 3 and 6 months (TSH: $2.5 \pm 1.1$ vs $2.5 \pm 1.1$ and $2.4 \pm 1.1 \mathrm{mIU} / \mathrm{l}$ respectively, $\mathrm{fT}_{4}: 12.4 \pm 2.4 \mathrm{vs} 12.5 \pm 2.4$ and $12.3 \pm 2.1 \mathrm{pg} / \mathrm{ml}$ respectively, and $\mathrm{fT}_{3}: 3.4 \pm 0.6 \mathrm{vs} 3.4 \pm 0.6$ and $3.3 \pm 0.5 \mathrm{pg} / \mathrm{ml}$ respectively).
\end{abstract}

Conclusion: Oral liquid $\mathrm{L}-\mathrm{T}_{4}$ formulations could diminish the problem of $\mathrm{L}-\mathrm{T}_{4}$ malabsorption caused by coffee when using traditional tablet formulations.

\section{Introduction}

Levothyroxine ( $\mathrm{L}-\mathrm{T}_{4}$ ) is the most effective drug used in replacement therapy for patients with hypothyroidism worldwide, representing the fourth most common medication dispensed in the United States in the last few years (1). Approximately $60-90 \%$ of a $\mathrm{L}-\mathrm{T}_{4}$ dose is absorbed within $3 \mathrm{~h}$ of ingestion. Most of the absorption takes place in the jejunum and ileum (2), and the absorption is maximal when it is taken on an empty stomach, reflecting the importance of gastric acidity in the process. Due to this, $\mathrm{L}^{-} \mathrm{T}_{4}$ is usually taken with water in the morning before breakfast (3). Taking $\mathrm{L}_{-} \mathrm{T}_{4}$ with coffee, or with water (c) 2014 European Society of Endocrinology Printed in Great Britain
European Journal of

Endocrinology

(2014) 170, 95-99 followed by coffee within a few minutes, results, in fact, in poor TSH response in many patients (4). Traditionally, $\mathrm{T}_{4}$ is available in tablet form worldwide, but novel formulations in soft gel capsule or liquid form are available now.

We fortuitously observed an euthyroid patient who wrongly consumed liquid $\mathrm{L}_{\mathrm{T}} \mathrm{T}_{4}$ with coffee at breakfast; after changing the time of consumption to $30 \mathrm{~min}$ before breakfast, no change in $\mathrm{TSH}_{1} \mathrm{fT}_{4}$, and $\mathrm{fT}_{3}$ concentrations was observed. Once the first patient was identified, we identified 53 additional stable euthyroid patients who consumed liquid $\mathrm{L}_{\mathrm{T}} \mathrm{T}_{4}$ with coffee. 
The aim of this study was to compare the $\mathrm{TSH}, \mathrm{fT}_{4}$, and $\mathrm{fT}_{3}$ concentrations of patients taking liquid $\mathrm{L}-\mathrm{T}_{4}$ at breakfast with those observed after the consumption of the same dosage 30 min before breakfast 3 and 6 months later.

\section{Subjects and methods}

Patients were recruited by searching the database of patients treated and followed up at the Thyroid Unit of the Department of Clinical and Experimental Sciences, University of Brescia. The search criteria were as follows: i) treatment of hypothyroidism with liquid $\mathrm{L}^{-\mathrm{T}_{4}}$ (IBSA Farmaceutici Italia srl, Lodi, Italy); ii) complete personal medical history; and iii) details on current drug therapy and any previous therapy. Patients fulfilling the above criteria were then contacted by phone to ask them whether they took $\mathrm{L}^{-} \mathrm{T}_{4}$ at breakfast.

All the patients were submitted to $\mathrm{TSH}_{1} \mathrm{fT}_{4}$, and $\mathrm{fT}_{3}$ evaluation, with the indication that the same dosage of $\mathrm{L}^{-\mathrm{T}_{4}}$ be consumed $30 \mathrm{~min}$ before breakfast. After 3 and 6 months, their serum $\mathrm{TSH}, \mathrm{fT}_{4}$, and $\mathrm{fT}_{3}$ concentrations were determined again.

Serum concentrations of free $\mathrm{T}_{4}$ ( $\mathrm{fT}_{4}$; normal range: 8.0-19.0 pg/ml, analytical sensitivity: $1 \mathrm{pg} / \mathrm{ml}$; intra- and interassay coefficients of variation $(\mathrm{CV}): 2.4$ and $6.8 \%$ respectively), free tri-iodothyronine ( $\mathrm{fT}_{3}$; normal range: 2.4-4.7 pg/ml; analytical sensitivity: $0.35 \mathrm{pg} / \mathrm{ml}$; intraand interassay CV: 4.6 and 6.5\% respectively), and TSH (normal range: $0.4-4.5 \mathrm{mIU} / 1$, analytical sensitivity: $0.004 \mathrm{mIU} / \mathrm{l}$; intra- and interassay $\mathrm{CV}$ : 2.5 and $5.7 \%$ respectively) were measured by means of immunochemiluminescent assays using an automated analyzer (Immulite 2000, DPC Cirrus, Los Angeles, CA, USA) employing commercial kits (Diagnostic Products Corporation, Los Angeles, CA, USA).

\section{Statistical analysis}

Statistical analysis was carried out using the SPSS Software (SPSS, Inc.). Between-group comparisons of thyroid profile at baseline, 3 months, and 6 months were made by ANOVA. A $P$ value $<0.05$ was considered statistically significant. Data are expressed as mean \pm s.D.

\section{Results}

Among 545 patients on liquid $\mathrm{L}^{-} \mathrm{T}_{4}$ treatment, 54 (9.9\%) subjects (48 females and six males) fulfilled the inclusion criteria and were recruited for this study. All the patients were euthyroid (TSH: $2.5 \pm 1.1 \mathrm{mIU} / 1, \mathrm{fT}_{4}: 12.4 \pm$ $2.4 \mathrm{pg} / \mathrm{ml}, \mathrm{fT}_{3} 3.4 \pm 0.6 \mathrm{pg} / \mathrm{ml}$ ) and undergoing treatment with $\mathrm{L}^{-\mathrm{T}_{4}}$ (mean dosage: $73.15 \pm 17.41 \mu \mathrm{g} /$ day). In detail, 41 patients (37 females and four males) consumed $\mathrm{L}^{-\mathrm{T}_{4}}$ with water at breakfast followed by coffee intake within a few minutes (group A) and 13 patients (11 females and two males) consumed $\mathrm{L}_{-} \mathrm{T}_{4}$ with coffee (group B). Table 1 summarizes the clinical and biochemical parameters of patients at recruitment. The two groups were superimposable for age, mean $\mathrm{L}^{-} \mathrm{T}_{4}$ dosage, and $\mathrm{fT}_{4}$ and $\mathrm{fT}_{3}$ values. A slightly, but not significant, higher TSH value was observed among patients in group B than among those in group A $(2.9 \pm 0.9$ vs $2.3 \pm 1.1 \mathrm{mIU} / 1$ respectively).

No difference in thyroid hormone profile was observed after 3 and 6 months of taking $\mathrm{L}^{-\mathrm{T}_{4}} 30 \mathrm{~min}$ before breakfast with respect to that recorded at recruitment: TSH $(2.5 \pm 1.1$ and $2.4 \pm 1.1$ vs $2.5 \pm 1.1 \mathrm{mIU} / 1$ respectively), $\mathrm{fT}_{4}(12.5 \pm 2.4$ and $12.3 \pm 2.1$ vs $12.4 \pm$ $2.4 \mathrm{pg} / \mathrm{ml}$ respectively), and $\mathrm{fT}_{3}(3.4 \pm 0.6$ and $3.3 \pm 0.5 \mathrm{vs}$ $3.4 \pm 0.6 \mathrm{pg} / \mathrm{ml}$ respectively). Similar findings were observed when the whole cohort was divided into groups $\mathrm{A}$ and $\mathrm{B}$ (Table 2).

\section{Discussion}

The main finding of this study is that oral liquid $\mathrm{T}_{4}$ can be taken at breakfast both with water and with coffee. As known, $\mathrm{L}_{-} \mathrm{T}_{4}$ is a drug used worldwide for the treatment of hypothyroidism or suppressive therapy of goiter and cancer $(5,6) . \mathrm{L}^{-\mathrm{T}_{4}}$ is one of the most widely dispensed medications in the world, representing the fourth most

Table 1 Clinical and biochemical parameters of patients at recruitment.

\begin{tabular}{|c|c|c|c|}
\hline & Group A $(n=41)$ & Group $\mathbf{B}(n=13)$ & $P$ value \\
\hline Age (years) & $48.7 \pm 11.1$ & $51.7 \pm 12.6$ & 0.413 \\
\hline $\mathrm{L}-\mathrm{T}_{4}$ dosage ( $\mu \mathrm{g} /$ day) & $76.9 \pm 16.1$ & $71.9 \pm 17.8$ & 0.375 \\
\hline $\mathrm{TSH}(\mathrm{mIU} / \mathrm{l})$ & $2.3 \pm 1.1$ & $2.9 \pm 0.9$ & 0.056 \\
\hline $\mathrm{fT}_{4}(\mathrm{pg} / \mathrm{ml})$ & $12.3 \pm 2.4$ & $12.5 \pm 2.4$ & 0.850 \\
\hline $\mathrm{fT}_{3}(\mathrm{pg} / \mathrm{ml})$ & $3.4 \pm 0.6$ & $3.4 \pm 0.5$ & 0.734 \\
\hline
\end{tabular}


Table 2 Thyroid profile of patients consuming $\mathrm{L}_{4}$ at breakfast and after 3 and 6 months of changing the time of consumption $30 \mathrm{~min}$ before breakfast.

\begin{tabular}{|c|c|c|c|c|}
\hline & \multicolumn{4}{|c|}{ Group A $(n=41)$} \\
\hline & At recruitment ${ }^{a}$ & 3 months $^{b}$ & 6 months $^{b}$ & $P$ \\
\hline TSH (mIU/l) & $2.3 \pm 1.1$ & $2.3 \pm 1.1$ & $2.3 \pm 1.0$ & 0.939 \\
\hline $\mathrm{fT}_{4}(\mathrm{pg} / \mathrm{ml})$ & $12.2 \pm 2.5$ & $12.3 \pm 2.5$ & $12.3 \pm 2.0$ & 0.479 \\
\hline $\mathrm{fT}_{3}(\mathrm{pg} / \mathrm{ml})$ & $3.4 \pm 0.6$ & $3.3 \pm 0.6$ & $3.2 \pm 0.6$ & 0.079 \\
\hline
\end{tabular}

\begin{tabular}{|c|c|c|c|}
\hline \multicolumn{4}{|c|}{ Group B $(n=13)$} \\
\hline At recruitment ${ }^{a}$ & 3 months $^{b}$ & 6 months $^{b}$ & $P$ \\
\hline $2.9 \pm 0.9$ & $2.9 \pm 0.9$ & $2.8 \pm 0.9$ & 0.323 \\
\hline $12.9 \pm 2.0$ & $12.5 \pm 2.5$ & $12.3 \pm 2.3$ & 0.208 \\
\hline $3.4 \pm 0.7$ & $3.5 \pm 0.6$ & $3.5 \pm 0.4$ & 0.615 \\
\hline
\end{tabular}

$P$ values based on ANOVA

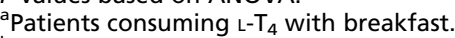

${ }^{\mathrm{b}}$ After changing the time of $\mathrm{L}^{-} \mathrm{T}_{4}$ consumption $30 \mathrm{~min}$ before breakfast.

common medication dispensed in the United States in the last few years (1).

Approximately $60-90 \%$ of a $\mathrm{L}-\mathrm{T}_{4}$ dose is absorbed within $3 \mathrm{~h}$ of ingestion. It is recommended that $\mathrm{L}-\mathrm{T}_{4}$ be taken on an empty stomach, as food, and also many drugs, can reduce its absorption (3). Gastric acidity plays an important role in the absorption of $\mathrm{L}^{-} \mathrm{T}_{4}$, as has also been shown by Centanni et al. (7). In fact, patients with Helicobacter pylori-related gastritis or atrophic gastritis require an increased dose of $\mathrm{L}_{\mathrm{L}} \mathrm{T}_{4}$, underlining the importance of normal gastric acid secretion for the dissociation and absorption of a $\mathrm{L}-\mathrm{T}_{4}$ tablet (7).

A recent trial in which patients taking $\mathrm{L}_{4} \mathrm{~T}_{4}$ were switched to three different ingestion modalities ( $\mathrm{L}-\mathrm{T}_{4}$ prior to breakfast, during breakfast, or after dinner) has shown that pre-breakfast fasting is associated with the highest intestinal absorption of the hormone (8).

In addition, Benvenga et al. (4) have clearly demonstrated a failure in the normalization of TSH values in patients consuming $\mathrm{L}-\mathrm{T}_{4}$ tablets with coffee or with water followed by coffee intake within a few minutes. Studies carried out in volunteers under an acute oral loading of $\mathrm{L}-\mathrm{T}_{4}$ with either water or coffee and in vitro studies have confirmed the interference of coffee (4).

Despite the 'classical' tablet formulation of $\mathrm{T}_{4}$, recently, pharmaceutical industries have introduced other formulations such as soft gel capsule and liquid in a few countries. Soft gel capsule seemed to diminish the problem of $\mathrm{L}^{-} \mathrm{T}_{4}$ malabsorption caused by coffee when using traditional 'tablets' at least in eight volunteers (9).

Compliance with medical recommendations, especially with drug therapy, has been recognized as challenging (10); in particular, a significant number of patients found it difficult to comply with $\mathrm{L}-\mathrm{T}_{4}$ therapy as they had to postpone taking coffee by $1 \mathrm{~h}$ (9). This is of great social relevance if we assume that subjects with a worst adherence to $\mathrm{L}-\mathrm{T}_{4}$ therapy are more likely to show variability in TSH concentrations (11). This means that these patients should be monitored more closely, increasing the direct and indirect costs of health.

To the best of our knowledge, this is the first report to show a comparable thyroid hormonal profile in patients consuming oral liquid $\mathrm{L}-\mathrm{T}_{4}$ prior to breakfast within the very first few minutes, but more interesting at breakfast, into the coffee. If our observation is confirmed in larger prospective studies, liquid formulation could simplify the compliance with $\mathrm{L}-\mathrm{T}_{4}$ therapy, with a theoretical reduction in health costs. Our observation gives rise to many questions about the possible different molecular properties, stability, and absorption of liquid $\mathrm{L}-\mathrm{T}_{4}$ compared with the tablet form.

Indeed, Yue et al. (12) have shown that absorption levels are similar for both tablet and liquid formulations, although the liquid formulation reached the systemic circulation quicker as dissolution was not required prior to absorption. Our group has recently shown a reversible normalization of serum TSH levels in patients submitted to bariatric surgery after switching from the tablet form of $\mathrm{L}-\mathrm{T}_{4}$ to an oral liquid formulation. The fact that the switch from a tablet to an oral formulation normalized serum TSH levels and that switching back to the tablet formulation led to a worsening of TSH levels leads us to believe that the absorption of $\mathrm{T}_{4}$ is greater when used as an oral liquid formulation in our patients at least after bariatric surgery (13).

Drug dissolution and solubility may be altered by an increase in gastric $\mathrm{pH}$. Indeed, liquid $\mathrm{L}_{-} \mathrm{T}_{4}$ does not need to be dissolved before being absorbed, as has been shown recently by Yue et al. (12). It is conceivable that liquid $\mathrm{L}-\mathrm{T}_{4}$ formulations could also circumvent the $\mathrm{pH}$ alteration resulting from gastric bypass. Another hypothesis is that the presence of alcohol (only in liquid formulations) could play a key role in the absorption of $\mathrm{T}_{4}$. Indeed, oral mucosal drug delivery is known as an alternative method for systemic drug delivery offering several advantages over 
both injectable and enteral methods (14). Because the oral mucosa is highly vascularized, drugs that are absorbed through the oral mucosa directly enter the systemic circulation, bypassing the gastrointestinal tract (14). Consistent with this hypothesis, we would expect to see more rapid pharmacokinetics if oral liquid $\mathrm{T}_{4}$ can be absorbed by oral mucosa. In agreement with this hypothesis, it has been demonstrated that a liquid formulation exhibits a faster time to maximal concentration when compared with a tablet formulation (12). Further studies are needed to clarify this intriguing point.

Another major problem is the stability of liquid $\mathrm{L}-\mathrm{T}_{4}$. Taking into account our data obtained in patients taking the drug directly with coffee, we hypothesize that high temperatures (i.e. coffee temperature) do not alter the molecular properties or stability of $\mathrm{L}_{-} \mathrm{T}_{4}$. Studies on stability, carried out with tablet formulations, have shown that sodium $\mathrm{L}-\mathrm{T}_{4}$ gets rapidly degraded at $60^{\circ} \mathrm{C}$ $(15,16)$. Indeed, an Italian coffee 'espresso' is served at $80-90{ }^{\circ} \mathrm{C}(17)$. To our knowledge, no data on the stability of liquid $\mathrm{L}-\mathrm{T}_{4}$ at high temperatures are available in the scientific literature. Personal data (not published) on the degradation and stability of oral liquid $\mathrm{L}_{-} \mathrm{T}_{4}$ in different solvents (coffee also) at high temperatures do not indicate the alteration or modification of its chemical structure or alteration of its stability up to $20 \mathrm{~min}$. The only data available, obtained at cold temperatures $\left(4^{\circ} \mathrm{C}\right)$, indicate the greater stability of liquid formulations compared with tablet formulations (18).

This study has a few limitations. Dietary fiber and food structure are well-established factors that affect the intestinal absorption of $\mathrm{L}_{-} \mathrm{T}_{4}$ tablets (19). Even if we asked our patients to not change their breakfast, the dietary content is not available. However, even if we admit a modification in dietary content during the study-span, no patient showed an increase in thyreotropin level. This could mean that no change in dietary content has been made or that dietary content doesn't influence the absorption of oral liquid formulations.

Secondly, pharmacokinetic study and loading tests, the gold standard methods to assess intestinal absorption of drugs, were not carried out. Additional studies are needed to clarify these intriguing points.

In conclusion, we showed for the first time that liquid $\mathrm{L}-\mathrm{T}_{4}$ formulations could diminish the problem of $\mathrm{L}-\mathrm{T}_{4}$ malabsorption caused by coffee when using traditional tablet formulations. This could ameliorate the compliance of 'thyroid' patients, reducing, at the same time, the health expenditure.
Declaration of interest

The authors declare that there is no conflict of interest that could be perceived as prejudicing the impartiality of the research reported.

\section{Funding}

This research did not receive any specific grant from any funding agency in the public, commercial or not-for-profit sector.

\section{Author contribution statement}

C Cappelli and I Pirola designed the purpose of this study. E Gandossi and A Formenti did the literature search and selection and wrote the manuscript. C Cappelli, I Pirola, E Gandossi, A Formenti, and M Castellano collaborated equally in the literature search and selection and in the paper revision.

\section{References}

1 IMS National prescription audit ${ }^{\mathrm{tm}}$. Use of Meds in the U.S. review of 2010 in http://www.imshealth.com.

2 Gkotsina M, Michalaki M, Mamali I, Markantes G, Sakellaropulos GC, Kalfarentzos F, Vagenakis A \& Markou B. Improved levothyroxine pharmacokinetics after bariatric surgery. Thyroid 20134 414-419. (doi:10.1089/thy.2011.0526)

3 Lamson MJ, Pamplin CL, Rolleri RL \& Klein I. Quantitation of a substantial reduction in levothyroxine $\left(\mathrm{T}_{4}\right)$ absorption by food. Thyroid 200414876

4 Benvenga S, Bartolone L, Pappalardo MA, Russo A, Lapa D, Giorgianni G, Saraceno G \& Trimarchi F. Altered intestinal absorption of L-thyroxine caused by coffee. Thyroid 2008 18 293-301. (doi:10.1089/ thy.2007.0222)

5 Pacini F \& Castagna MG. Approach to and treatment of differentiated thyroid carcinoma. Medical Clinics of North America 201296 369-383. (doi:10.1016/j.mcna.2012.01.002)

6 Almandoz JP \& Gharib H. Hypothyroidism: etiology, diagnosis, and management. Medical Clinics of North America 201296 203-221. (doi:10.1016/j.mcna.2012.01.005)

7 Centanni M, Gargano L, Canettieri G, Viceconti N, Franchi A, Delle Fave $\mathrm{G} \&$ \& Annibale B. Thyroxine in goiter, Helicobacter pylori infection, and chronic gastritis. New England Journal of Medicine 2006 354 1787-1795. (doi:10.1056/NEJMoa043903)

8 Bach-Huynh TG, Nayak B, Loh J, Soldin S \& Jonklaas J. Timing of levothyroxine administration affects serum thyrotropin concentration. Journal of Clinical Endocrinology and Metabolism 200994 3905-3912. (doi:10.1210/jc.2009-0860)

9 Vita R, Saraceno G, Trimarchi F \& Benvenga S. A novel formulation of L-thyroxine $\left(\mathrm{L}-\mathrm{T}_{4}\right)$ reduces the problem of $\mathrm{L}-\mathrm{T}_{4}$ malabsorption by coffee observed with traditional tablet formulations. Endocrine $2013 \mathbf{4 3}$ 154-160. (doi:10.1007/s12020-012-9772-2)

10 Düsing R, Lottermoser K \& Mengden T. Compliance with drug therapy - new answers to an old question. Nephrology, Dialysis, Transplantation 200116 1317-1321. (doi:10.1093/ndt/16.7.1317)

11 Perez CL, Araki FS, Graf H \& de Carvalho GA. Serum thyrotropin levels following levothyroxine administration at breakfast. Thyroid 201323 779-784. (doi:10.1089/thy.2012.0435)

12 Yue CS, Scarsi C \& Ducharme MP. Pharmacokinetics and potential advantages of a new oral solution of levothyroxine vs. other available dosage forms. Arzneimittel-Forschung 201262 631-636.

13 Pirola I, Formenti AM, Gandossi E, Mittempergher F, Casella C, Agosti B \& Cappelli C. Oral liquid L-thyroxine $\left(\mathrm{L}-\mathrm{T}_{4}\right)$ may be better absorbed compared to $\mathrm{L}_{-} \mathrm{T}_{4}$ tablets following bariatric surgery. Obesity Surgery 201323 1493-1496. (doi:10.1007/s11695-013-1015-y) 
14 Zhang H, Zhang J \& Streisand JB. Oral mucosal drug delivery: clinical pharmacokinetics and therapeutic applications. Clinical Pharmacokinetics 200241 661-680. (doi:10.2165/00003088-200241090-00003)

15 Won CM. Kinetics of degradation of levothyroxine in aqueous solution and in solid state. Pharmaceutical Research 19929 131-137. (doi:10.1023/A:1018952415732)

16 Collier JW, Shah RB, Gupta A, Sayeed V, Habib MJ \& Khan MA. Influence of formulation and processing factors on stability of levothyroxine sodium pentahydrate. AAPS PharmSciTech 201011 818-825. (doi:10.1208/s12249-010-9434-8)
17 Andueza S, Maeztu L, Pascual L, Ibanez C, Paz de Pena M \& Cid C. Influence of extraction temperature on the final quality of espresso coffee. Journal of the Science of Food and Agriculture 200383 240-248. (doi:10.1002/jsfa.1304)

18 Boulton DW, Fawcett JP \& Woods DJ. Stability of an extemporaneously compounded levothyroxine sodium oral liquid. American Journal of Health-System Pharmacy 199653 1157-1161.

19 Liwanpo L \& Hershman J. Conditions and drugs interfering with thyroxine absorption. Best Practice \& Research. Clinical Endocrinology \& Metabolism 200923 781-792. (doi:10.1016/j.beem.2009.06.006)

Received 22 August 2013

Revised version received 9 October 2013

Accepted 11 October 2013 